\title{
Role of S128R polymorphism of E-selectin in colon metastasis formation
}

\author{
Riccardo Alessandro $^{1 *}$, Gregorio Seidita ${ }^{1}$, Anna Maria Flugy ${ }^{1}$, Francesca Damiani ${ }^{1}$, Antonio Russo ${ }^{2}$, Chiara Corrado ${ }^{1}$, \\ Paolo Colomba ${ }^{1}$, Lucia Gullotti ${ }^{1,3}$, Reinhard Buettner ${ }^{3}$, Loredana Bruno ${ }^{2}$ and Giacomo De Leo ${ }^{1}$ \\ ${ }^{1}$ Dipartimento di Biopatologia e Metodologie Biomediche, Sezione di Biologia e Genetica, Università di Palermo, Palermo, Italy \\ ${ }^{2}$ Dipartimento di Discipline Chirurgiche ed Oncologiche, Università di Palermo, Palermo, Italy \\ ${ }^{3}$ Institute of Pathology, University of Bonn, Bonn, Germany
}

\begin{abstract}
The extravasation of cancer cells is a key step of the metastatic cascade. Polymorphisms in genes encoding adhesion molecules can facilitate metastasis by increasing the strength of interaction between tumor and endothelial cells as well as impacting other properties of cancer cells. We investigated the Ser128Arg (a561c at the nucleotide level) polymorphism in the E-selectin gene in patients with metastatic colon cancer and its functional significance. Genotyping for a561c polymorphism was performed on 172 cancer patients and on an age-matched control population. The colon cancer group was divided into groups with $\left(\mathrm{M}^{+}\right)$and without observable metastasis $\left(\mathrm{M}^{-}\right)$. For in vitro functional assays, Huvec transfected cells expressing wild-type (WT) or the S128R variant of E-selectin were established to study in vitro binding ability and signal transduction processes of T84 colon cancer cell line. Our results demonstrated that the Arginine ${ }^{128}$ allele was more prevalent in the $\mathbf{M}^{+}$group than in the $\mathbf{M}^{-}$group or normal controls $(p<0.005$; odds ratio, $1.56 ; 95 \%$ confidence interval (CI) $1.16-1.92 ; p<0.001$, odds ratio $=1.65 ; \mathrm{CI}=1.24-1.99$, respectively). In vitro, S128R E-selectin transfected Huvec cells, supported increased adhesion as well as increased cellular signaling of T84 cancer cells compared to WT E-selectin and mock-transfected Huvec cells. These findings suggest that the E-selectin S128R polymorphism can functionally affect tumor-endothelial interactions as well as motility and signaling properties of neoplastic cells that may modulate the metastatic phenotype.

(C) 2007 Wiley-Liss, Inc.
\end{abstract}

Key words: E-selectin; colon cancer; genetic polymorphisms; metastasis; cell signaling

Metastasis is the main cause of death for cancer patients. Metastatic dissemination is a complex process, depending on the ability of malignant cells to escape from the primary tumor, penetrate and flow through the bloodstream, adhere to the vascular bed and then invade and proliferate in the organ parenchyma. ${ }^{1}$ Interactions of blood-borne carcinoma cells and the microvasculature are essential prerequisites for metastasis to occur. These processes involve mechanical contact and transient attachment, which are mediated by endothelial surface adhesion molecules and their ligands on the neoplastic cells. ${ }^{2}$ Factors mediating these interactions are therefore viewed as important determinants of the metastatic phenotype. Among the molecules mediating tumor-endothelium interactions are selectins. ${ }^{3-7}$ The selectins are a small family of intercellular adhesion molecules with 3 members: E-, P- and Lselectin. They share a mosaic structure consisting of an amino-terminal domain followed by an epidermal growth factor (EGF)-like domain, a variable number of complement regulatory repeats, a transmembrane domain and a short cytoplasmic domain. E-selectin (ELAM-1) is expressed by endothelial cells, which are activated by cytokines released during the inflammatory process and plays an important role in neutrophil extravasation into injured tissues as well as in neoplastic cell extravasation. ${ }^{8}$ A correlation between the expression of E-selectin, the E-selectin ligands (i.e., sialyl-LewisX or sialyl-LewisA) with the metastatic potential of malignant cells is best documented for colon carcinomas. ${ }^{9-12}$

Several findings regarding E-selectin polymorphisms have been described. ${ }^{13,14}$ The S128R polymorphism (a substitution of an uncharged serine with a positively charged arginine within the EGF domain) is of interest for 2 reasons: first, it is overrepresented in certain patient groups affected by disease characterized by an increased adhesiveness of leukocytes to endothelium such as atherosclerosis and myocardial infarction ${ }^{15,16}$ and second, it is a functional polymorphism since it modifies ligand affinity. ${ }^{17}$ Since there exists a mechanistic similarity between leukocyte and tumor-cell extravasation, it is therefore reasonable to hypothesize that naturally occurring E-selectin gene polymorphisms might underlie variations observed between individuals in their susceptibility to metastasis formation. However, the physiological importance of the S128R polymorphism in the pathogenesis of metastasis has not been explored yet.

In this study we have tested and affirmed the hypothesis that the S128R polymorphism frequency is significantly higher in patients with metastatic cancer compared to patients with localized disease without metastasis and healthy normal controls. We also demonstrate, through the use of an experimental model of Huvec cell transfectants, expressing wild-type and the variant form of ESelectin, that this polymorphism is able to affect the adhesion and motility of tumor cells as well as to functionally alter biochemical pathways, which may modulate the overall metastatic phenotype.

\section{Material and methods \\ Cell culture}

T84 (ICLC, Genova, Italy) human colon cancer cells were maintained in DMEM-F12 (BioWhittaker, Verviers, Belgium) supplemented with $10 \%$ fetal calf serum (FCS) (BioWhittaker, Verviers, Belgium), $100 \mathrm{U} / \mathrm{ml}$ penicillin and $100 \mu \mathrm{g} / \mathrm{ml}$ streptomycin (Euroclone, UK). Human umbilical vein endothelial cells (HUVEC) were obtained from Clonetics (Bio-Whittaker, Verviers, Belgium) and grown according to supplier's information. CHO cells (ICLC, Genova, Italy) were grown in F12 Ham's medium, supplemented with $10 \%$ fetal calf serum, $100 \mathrm{U} / \mathrm{ml}$ penicillin and $100 \mu \mathrm{g} / \mathrm{ml}$ streptomycin. All cells were maintained at $37^{\circ} \mathrm{C}$ under $5 \% \mathrm{CO}_{2}$ atmosphere. All other reagents were purchased from Sigma (St. Louis, MO), if not otherwise cited.

\section{E-selectin genotyping and statistical analysis}

The study involved 172 Caucasian patients with histologically confirmed diagnosis of colon cancer who were referred for treatment to the Oncology Unit at the University Hospital of Palermo, Italy. No subjects with a family history of early onset colon cancer or multiple cancer cases were included into the study. Metastasis were located in different organ sites and their distribution was in line with patterns observed in developed Western countries. ${ }^{18}$ Age of patients at diagnosis ranged from 57 to 85 (median, 64 years). Stage grouping is indicated in accordance with the guidelines of

Grant sponsors: Italian Association for Cancer Research (AIRC), Università di Palermo (International Cooperation), MURST, Fondazione Banco di Sicilia.

*Correspondence to: Dipartimento di Biopatologia e Metodologie Biomediche, Università di Palermo, Via Divisi 83, 90133 Palermo, Italy, Fondazione Banco di Sicilia. Fax: +091-655-4624. E-mail: ricale@unipa.it

Received 14 July 2006; Accepted after revision 12 February 2007

DOI 10.1002/ijc.22693

Published online 19 March 2007 in Wiley InterScience (www.interscience. wiley.com) 
TABLE I - CLINICAL CHARACTERISTICS OF COLON CANCER PATIENTS AND CONTROLS

\begin{tabular}{|c|c|c|}
\hline & Cancer patients & Controls \\
\hline & $n=172$ & $n=80$ \\
\hline & $n(\%)$ & $n(\%)$ \\
\hline $\begin{array}{l}\text { Median (range) age } \\
\text { Sex }\end{array}$ & Sex & 50 \\
\hline Male & $100(39.7)$ & $30(37.5)$ \\
\hline Female & $152(60.3)$ & $50(62.5)$ \\
\hline \multicolumn{3}{|l|}{ Lymph node status } \\
\hline $\begin{array}{l}\mathrm{pN}^{0} \\
\mathrm{pN}^{+}\end{array}$ & $\begin{array}{l}84(48.9) \\
88(51.1)\end{array}$ & \\
\hline \multicolumn{3}{|l|}{ Metastasis at diagnosis } \\
\hline Presence $\left(\mathrm{M}^{+}\right)$ & $90(52.4)$ & \\
\hline Absence $\left(\mathrm{M}^{-}\right)$ & $82(47.6)$ & \\
\hline \multicolumn{3}{|l|}{ Tumor location } \\
\hline Caecum & $22(12.7)$ & \\
\hline Ascending colon & $14(8.4)$ & \\
\hline Transverse colon & $15(8.7)$ & \\
\hline Descending colon & $18(10.7)$ & \\
\hline Sigmoid colon & $43(25)$ & \\
\hline Rectum & $60(34.5)$ & \\
\hline \multicolumn{3}{|l|}{ Tumor size $(\mathrm{cm})$} \\
\hline$<5$ & $70(40.6)$ & \\
\hline$>5$ & $102(59.4)$ & \\
\hline \multicolumn{3}{|l|}{ UICC stage } \\
\hline $\mathrm{I}$ & $54(31)$ & \\
\hline II & $30(17.5)$ & \\
\hline III & $62(36)$ & \\
\hline IV & $26(15.5)$ & \\
\hline
\end{tabular}

International Union Against Cancer. The characteristics of cancer patient and their tumors are reported in Table I.

A group of 80 age-matched Caucasians with no history of cancer, most of them blood donors, was recruited as control group. Informed consent was obtained from all participants. DNA was extracted from paraffin-embedded tumor tissue or from peripheral blood using a commercially available kit (QIAAmp, Qiagen, Hilden, Germany). To determine the distribution of E-Selectin Serine $^{128}$ and Arginine ${ }^{128}$ alleles in metastatic colon cancer patients and in control groups, the following primers were used: $5^{\prime}$-AAA ATC AAA GGC ACT CAG TAT AAG CA-3' (in the forward direction) and $5^{\prime}$-GAA CGT GAG ATG GTG CTA CCA-3' (in the reverse direction). PCR amplification was performed in a final volume of $30 \mu \mathrm{l}$ containing $200 \mathrm{ng}$ of DNA, $1.5 \mathrm{mM} \mathrm{MgCl}$, $10 \mathrm{mM}$ Tris- $\mathrm{HCl}(\mathrm{pH} 8.3), 50 \mathrm{mM} \mathrm{KCl}$ and $0.2 \mathrm{mM}$ each of dCTP, dATP, dTTP and dGTP (Amersham Pharmacia, Uppsala Sweden), each primer at $1.0 \mu \mathrm{M}$ and $1 \mathrm{U}$ of Taq polymerase (Amersham Pharmacia, Uppsala, Sweden) in a 9700 Applied Biosystem Thermocycler. PCR products $(229 \mathrm{bp})$ were visualized on $2 \%$ agarose gels with $10 \%$ ethidium bromide. The A to $\mathrm{C}$ transversion (a561c) abolishes a PstI restriction enzyme site, therefore genotyping was performed by PCR-RFLP with this enzyme. ${ }^{16}$ Subsequent confirmation of variants was performed by direct sequencing. Differences between groups were examined by $\chi^{2}$ test. The association of E-Selectin genotypes with the risk of metastasis was examined in terms of odds ratio (OR) and 95\% confidence intervals (CIs). For each OR, two-tailed probability values were calculated. All statistical analyses were done using SPSS version 10.0 (Chicago, IL). $p<0.05$ was assumed to be statistically significant. Because of their small number, E-Selectin Arginine ${ }^{128}$ homozygotes were grouped together for analysis with heterozygotes and treated as carriers for analysis.

Vector construction, transfection and isolation of stable transfectants

Human wild-type E-selectin cDNA cloned in the expression vector pMT2 was a gift from Dr. G. Kansas. ${ }^{19}$ The A to C transversion in cDNA position 561 was generated by QuikChange ${ }^{\mathbb{R}}$ II Site-Directed Mutagenesis Kits (Stratagene, La Jolla, CA) using primers a561c Forward (5'-CCAATACATCCTGCCGTGGCCACGGTGAAT-3') and a561c Reverse (5'-ATTCACCGTGGCCACGGCAGGATGTATTGG-3' ${ }^{\prime}$ ); procedure was made according to manufacturer's protocol. All mutant constructs were verified by sequencing in both orientations using the ABI Prism Big Dye Terminator Cycle Sequencing Ready Reaction Kit (vers. 1.1) and the ABI 310 Genetic Analyzer (Applied Biosystems, Foster City, CA).

Huvec were transfected in transient with wild-type (Huvec-ESWT), S128R E-Selectin (Huvec-ES-S128R) or empty plasmid using jetPEI ${ }^{\mathrm{TM}}$-HUVEC transfection kit (Polyplus-transfection, San Marcos, CA) according to the manufacture's instructions. Briefly, HUVEC were seeded at $3.5 \times 10^{4}$ cells/well in a 24 -well plate previously coated with collagen type I (Sigma, St. Louis, MO) and grown to 60-70\% confluence. For transfection, $2 \mu \mathrm{g}$ plasmid DNA was diluted in $50 \mu \mathrm{l}$ of $150 \mathrm{mM} \mathrm{NaCl}$ solution and mixed with $50 \mu \mathrm{l}$ of $150 \mathrm{mM} \mathrm{NaCl}$ solution containing $4 \mu \mathrm{l}$ of polymer complexes of jetPEI-HUVEC DNA transfection reagent. After $30 \mathrm{~min}$ of incubation, the mixture was added dropwise onto the well and homogenized by gently swirling the plate. The plate was incubated at $37^{\circ} \mathrm{C}$ and $5 \% \mathrm{CO}_{2}$ in a humidified atmosphere for $4 \mathrm{hr}$ and thereafter medium was replaced with HUVEC growth medium.

In some set of experiments Chinese hamster ovary (CHO) cells engineered to express wild-type or polymorphic E-selectin were used. For this purpose, $\mathrm{CHO}$ were stable transfected with wildtype (CHO-ES-WT), S128R E-Selectin (CHO-ES-S128R) or empty plasmid using LipofectAMINE 2000 (Invitrogen Corporation, Carlsbad, CA). Briefly, CHO cells were plated onto 12-well tissue culture plates (CoStar, Cambridge, MA) and grown to 70 $80 \%$ confluence. Each well was inoculated with $500 \mu \mathrm{l}$ of OptiMEM (InVitrogen Life Technologies, Carlsbad, CA) containing LipofectAMINE 2000 at $8 \mu \mathrm{g} / \mathrm{ml}$ and the vector constructs at 2 $\mu \mathrm{g} / \mathrm{ml}$ for $4 \mathrm{hr}$. Cells were further incubated overnight with the addition of $500 \mu \mathrm{l} /$ well of regular CHO medium consisting of $\alpha$ minimal essential medium (MEM) supplemented with $10 \%$ fetal calf serum and $2 \mathrm{mM}$ 1-glutamine, washed and replaced with $\mathrm{CHO}$ medium. Successfully transfected cells were selected by the addition of $3 \mu \mathrm{g} / \mathrm{ml}$ of puromycin.

\section{Conditioned medium}

CHO-ES-WT, CHO-ES-S128R and mock-transfected cells were grown to confluence, washed several times in PBS and then incubated with serum-free medium for $48 \mathrm{hr}$. The conditioned medium $(\mathrm{CM})$ was centrifuged at low speed to remove cell debris and then stored at $-80^{\circ} \mathrm{C}$ until used for motility and invasion assays.

\section{Cell-binding assays to E-selectin expressing Huvec}

HUVEC-ES-WT, HUVEC-ES-S128R cells and mock-transfected cells were grown to confluence in 24-well tissue culture plates. HUVEC cells were fixed as previously described. ${ }^{9}$ Briefly cells were fixed with glutaraldehyde $0.0125 \%$ (Agar Scientific, Stanted, Essex, UK) and then treated with $10 \mathrm{mM}$ ethanolamine to block free aldehydic groups and washed several times before plating the cancer cells. T84 cells were detached with $10 \mathrm{mM}$ PBS/ EDTA, resuspended at $30 \times 10^{4}$ cells $/ \mathrm{ml}$ in plain medium containing $0.5 \%$ BSA and allowed to attach for $15 \mathrm{~min}$ on the fixed HUVEC monolayer. After this, gentle washing was performed with PBS and 300- $\mu$ l fresh medium was added into each well. Forty microliters of a $5 \mathrm{mg} / \mathrm{ml}$ stock solution of MTT was added to the cells, followed by an incubation at $37^{\circ} \mathrm{C}$ for $5 \mathrm{hr}$. After this period, the supernatants were decanted and $300 \mu \mathrm{l}$ of $100 \%$ DMSO was added. Stained products were released from the cells after shaking for $10 \mathrm{~min}$. Cell absorbance was measured at $550 \mathrm{~nm}$ with a spectrophotometric plate reader (Bio-Tek Instruments, Winooski, VT). For inhibition experiments, a monoclonal antibody against E-selectin (1.2B6, Santa Cruz Biotechnology, Santa Cruz, CA) or a control antibody of the same isotype (Santa Cruz 
Biotechnology, Santa Cruz, CA) was preincubated with the HUVEC monolayer at $2 \mu \mathrm{g} /$ well for $1 \mathrm{hr}$ prior to the adhesion assays.

\section{Migration assay}

Tumor-cell motility was studied using a 48-well chemotaxis chamber (Neuroprobe, Cabin John, MD) with a gelatin-coated polycarbonate filter $(12 \mu \mathrm{M}$ pore size $)$. About $2 \times 10^{6}$ cells $/ \mathrm{ml}$ were placed in the top wells and incubated for $16 \mathrm{hr}$. CM from transfectants was added in the bottom wells. At the end of assay, filters were removed and the membranes fixed and then stained with Diff-Quick. Each test group was assayed in quadruplicate. Five high-power $(400 \times)$ fields were counted and the results were expressed as number of cell present/high power field.

As indicated, a monoclonal antibody against E-selectin or a control antibody of the same isotype was added at $2 \mu \mathrm{g} / \mathrm{ml}$ in the bottom well with the $\mathrm{CM}$ and migration quantified as mentioned earlier.

\section{Western blot}

Mock- and E-selectin-transfected HUVEC cells were grown and fixed as mentioned earlier. T84 cells were added to the HUVEC monolayer. Adherent cells were recovered and lysed in buffer $(300 \mathrm{mM} \mathrm{NaCl}, 50 \mathrm{mM}$ Tris- $\mathrm{HCl} \mathrm{pH} 7.6,0.1 \%$ Triton, $1 \mathrm{mM}$ PMSF, $10 \mu \mathrm{g} / \mathrm{ml}$ Leupeptin, $10 \mu \mathrm{g} / \mathrm{ml}$ Aprotinin, $4 \mathrm{mM}$ EDTA, $2 \mathrm{mM}$ sodium orthovanadate, $10 \mathrm{mM} \mathrm{PP}_{\mathrm{I}}$ and $100 \mathrm{mM}$ $\mathrm{NaF}$ ) on ice for $1 \mathrm{hr}$. The lysates were clarified at high speed centrifugation for $15^{\prime}$ and an aliquot of the supernatant was assayed to determine protein concentration. Equal amounts of proteins were separated by a $6 \%$ SDS-polyacrylamide gel electrophoresis and transferred to nitrocellulose membrane (Protran Schleicher\&Schuell, Germany). The membrane was incubated in block solution (1 M glycine, $1.25 \%$ dry milk and $0.1 \%$ ovalbumine), and probed overnight with antiphosphotyrosine antibody (PY20; Santa Cruz Biotechnology, CA). After 3 washes with WS the membrane was incubated with horseradish peroxidase-conjugated secondary antibody and proteins were detected by the enhanced chemiluminescence detection system (Super Signal, Pierce, Rockford, IL). The blots were stripped and reprobed with antiactin antibodies (Cell Signaling Technology, Beverly, MA) to ensure equal loading and transfer of proteins. For p44/42 MAP kinase (ERK 1/2) and phospho-p44/42 MAP kinase (p-ERK 1/2) protein level evaluation the cell lysates were separated by SDSpolyacrylamide gel electrophoresis, transferred to nitrocellulose membrane and then the membrane was probed overnight at $4^{\circ} \mathrm{C}$ with specific antibodies against ERK 1/2 (Cell Signaling Technology, Beverly, MA) and p-ERK 1/2 (Cell Signaling Technology, Beverly, MA), respectively. Proteins corresponding to ERK $1 / 2$ and p-ERK $1 / 2$ were identified by using the detection protocol mentioned earlier.

\section{Immunofluorescence}

T84 cells were plated at $3 \times 10^{5}$ cells/well on a confluent mock- and E-selectin-transfected fixed $\mathrm{CHO}$ monolayer. After $3 \mathrm{hr}$, cells were washed with PBS, fixed in $3.7 \%$ paraformaldehyde for $10^{\prime}$, permeabilized for $5^{\prime}$ with $0.5 \%$ Triton X-100 and blocked in $1 \%$ BSA for $60^{\prime}$. Cells were incubated with an antiphosphotyrosine antibody for $60^{\prime}$ at $37^{\circ} \mathrm{C}$, washed 3 times with PBS and then incubated with the fluorescein-conjugated secondary antibody for $60^{\prime}$. After several washes, coverslips were mounted in moviol and viewed by fluorescence microscopy (Olympus BX50). For the quantification of total levels of phosphotyrosine images were taken from 10 different fields with identical acquisition parameters, and the mean of intensity was measured using photoshop 7.0 software (Adobe), values were background-corrected by regions outside the cells.
TABLE II - E-SELECTIN GENOTYPES IN PATIENTS AND CONTROLS

\begin{tabular}{|c|c|c|c|c|c|c|}
\hline \multirow[t]{2}{*}{ Genotype } & \multicolumn{2}{|c|}{ Controls } & \multicolumn{2}{|c|}{$\begin{array}{c}\text { Nonmetastatic } \\
\left(\mathrm{M}^{-}\right)\end{array}$} & \multicolumn{2}{|c|}{$\begin{array}{c}\text { Metastatic } \\
\left(\mathrm{M}^{+}\right)\end{array}$} \\
\hline & No. & $\%$ & No. & $\%$ & No. & $\%$ \\
\hline aa & 72 & 90 & 72 & 87.8 & 63 & 70 \\
\hline $\mathrm{ac}+\mathrm{cc}$ & 8 & 10 & 10 & 12.2 & 27 & 30 \\
\hline $\mathrm{c}$ allele frequency & \multicolumn{2}{|c|}{0.05} & \multicolumn{2}{|c|}{0.09} & \multicolumn{2}{|c|}{0.175} \\
\hline
\end{tabular}

$\mathrm{M}^{+}$vs. healthy controls $p=0.001 ; \mathrm{M}^{+}$vs. $\mathrm{M}^{-}=0.005 ; \mathrm{M}^{-}$vs. healthy controls $p=0.657$.

\section{Results \\ Distribution of genotypes}

Of 90 metastatic colon cancer patients tested, 63 (70\%) were homozygous for the E-Selectin Serine ${ }^{128}$ allele, 23 (25.6\%) were heterozygous S128R and 4 (4.4\%) were homozygous for the Arginine $^{128}$ allele. Concerning the 82 nonmetastatic colon cancer patients, $72(87.8 \%)$ were homozygous for the E-Selectin Serine $^{128}$ allele, $8(9.8 \%)$ were heterozygous S128R and $2(2.4 \%)$ were homozygous for the Arginine ${ }^{128}$ allele. For both categories, the homozygous Arginine 128 genotypes were not analyzed separately because of insufficient power but were grouped with the heterozygotes for statistical analyses. The genotypic distribution of the wild-type E-selectin allele in healthy controls was found similar to values observed in previous studies in Caucasian population. ${ }^{15,20}$

As shown in Table II, there was a statistically significant correlation between the E-selectin Arginine ${ }^{128}$ allele and the $\mathrm{M}^{+}$subgroup $v s$. controls $(p=0.001, \mathrm{OR}=1.65 ; \mathrm{CI}=1.24-1.99)$ and vs. $\mathrm{M}^{-}$subgroup $(p=0.005, \mathrm{OR}=1.56 ; \mathrm{CI}=1.16-1.92)$ indicating an association between the polymorphic allele and cancer progression. The frequency of a561c allele showed no statistical difference between M-patients and controls $(p=0.657)$.

\section{Expression of S128R E-selectin in HUVEC modulates colon} cancer cell adhesion and motility

The effect of expression of E-selectin wild-type and the a561c polymorphic allele was evaluated in transfected HUVEC cells with the aim to investigate the role of this naturally occurring polymorphism on cancer cell adhesion and motility. We have previously demonstrated that T84 colon carcinoma cells are endowed with the proper surface receptors to recognize and adhere to Eselectin. ${ }^{21,22}$ Figure $1 a$ shows that HUVEC-ES-S128R cells support significantly greater levels of T84 cell adhesion than HUVEC-ES-WT and mock-transfected HUVEC cells. Significantly, the percentage of adhesion of cancer cells to HUVEC-ESWT was comparable to that achieved when T84 cells are plated on TNF- $\alpha$ stimulated endothelial cells. ${ }^{9}$ To confirm that the attachment of colon cancer cells was mediated by E-selectin, we used the E-selectin blocking monoclonal antibody (1.2B6) in our adhesion assay; pretreatment of transfectants HUVEC cells with 1.2B6 antibody significantly inhibited T84 cell adhesion compared to mock-transfected cells $(p<0.05)$. Similar results were obtained using E-selectin transfected $\mathrm{CHO}$ cells (data not shown).

Studies have demonstrated that a soluble isoform of E-selectin (sE-selectin) is rapidly shed from the cellular surfaces and that it acts as a monocyte chemotactic agent. ${ }^{23,24}$ To examine the hypothesis that sE-selectin might stimulate motility of cancer cells, $\mathrm{CM}$ from $\mathrm{CHO}$ transfectants was used in Boyden chamber chemotaxis assays. CM was prepared from $\mathrm{CHO}$-transfected cells since primary endothelial cells are sensitive to serum-free condition. CM from CHO-ES-S128R cells induced T84 cells chemotaxis at significantly higher levels when compared with $\mathrm{CM}$ from CHOES-WT- (1.7-fold increase) and mock-transfected cells (2.5-fold increase) (Fig. 1b). To demonstrate the involvement of sE-selectin in T84-stimulated motility, CM was added to the Boyden chamber in the presence of 1.2B 6 anti E-selectin antibody. The incubation of $\mathrm{CM}$ with the antibody decreased cancer cells chemotaxis when compared with the effects mediated by isotype control antibody 


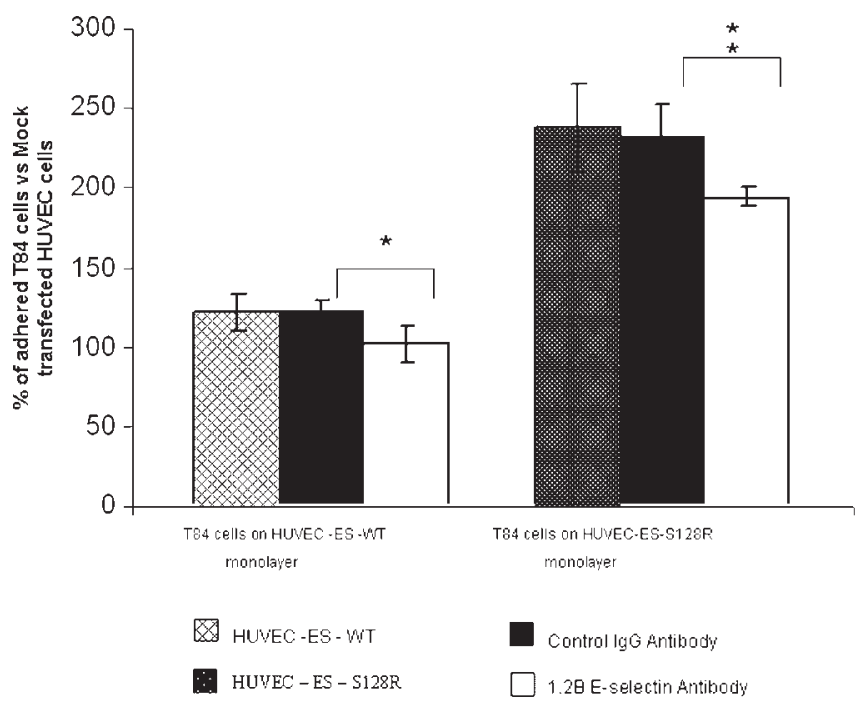

(a)

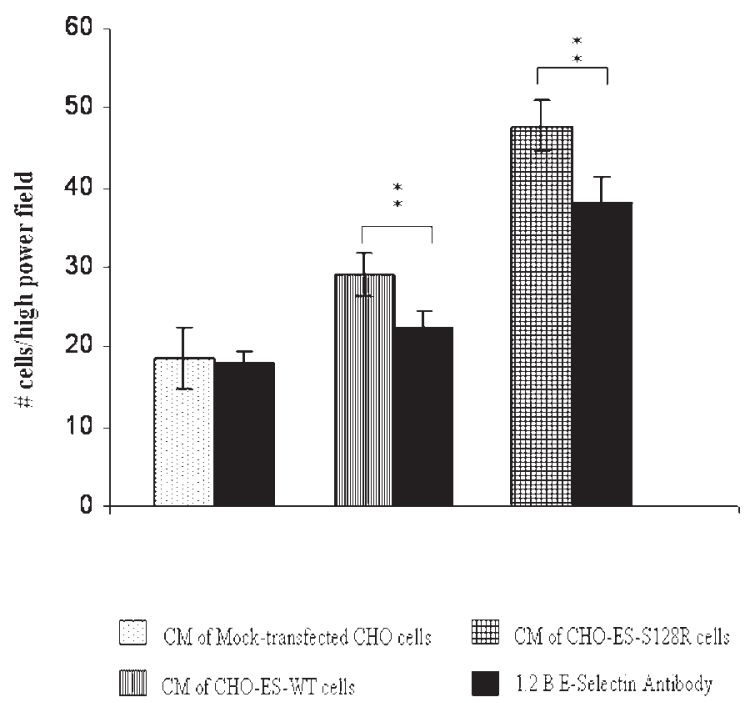

(b)

Figure 1 - Functional assays of T84 cells on Huvec cells transfected with E-selectin $\operatorname{Arg}^{128}$ or $\operatorname{Ser}^{128}$ cDNA. (a) Adhesion of T84 cells to a monolayer of Huvec cells expressing WT, S128R E-selectin or mock vector. Plating of cancer cells on Huvec-ES-S128R monolayer resulted in a 2 -fold increase of adhesion compared to cell attachment on Huvec-ES-WT monolayer. Treatment of Huvec monolayer with anti-E-selectin antibody caused a $20 \%$ inhibition of cell attachment. A matched isotype antibody used as control does not exert any effect on cell adhesion $(*=$ $p<0.05 ; * *=p<0.01$, when comparing two groups as indicated). (b) Stimulation of cancer cell motility by CM of transfectants CHO. CM from CHO-ES-S128R stimulates a higher T84 chemotaxis with respect to cell motility induced by medium from CHO-ES-WT cells (1.7-fold increase). Addition of anti-E-selectin antibody to $\mathrm{CM}$ of $\mathrm{CHO}$ cells inhibited the directional migration of the cells in response to $\mathrm{CM}$ (** $=p<$ 0.01 , when comparing 2 groups as indicated). Results presented are representative of $n=3$ experiments, each one done in quadruplicate.

$(p<0.05)$. Data are representative of 3 independent experiments each done in quadruplicate.

\section{Modulation of signaling pathways in colon cancer cells adhering to S128R transfected HUVEC cells}

To explore a functional consequence of the S128R polymorphism in E-Selectin-stimulated signaling, IP/Western blot analyses were carried out using lysates prepared from T84 colon cancer cells after adhesion to HUVEC-ES-S128R, HUVEC-ES-WT cells and mock-transfected HUVEC cells. As a marker for signal transduction, we initially looked at cellular tyrosine phosphorylation; immunoprecipitation/western blot analyses with a monoclonal antibody that specifically recognize phosphorylated tyrosine residues allowed to detect changes in global cellular tyrosine phosphorylation. As shown in Figure $2 a$ (upper panel), adhesion of colon cancer cells to HUVEC-ES-WT cells caused an increase in tyrosine phosphorylation of proteins corresponding approximately to molecular sizes of $45,60,85,120$ and $180 \mathrm{kDa}$ compared to the adhesion of tumor cells to mock-transfected HUVEC cells. Tyrosine phosphorylation signaling was further increased in T84 cells adhering to HUVEC-ES-S128R cells suggesting that this polymorphism may affect E-selectin ligand-mediated signal transduction in cancer cells. This conclusion was also strengthened by the evidence that the addition of a neutralizing anti-E-selectin antibody resulted in a pronounced reduction of tyrosine phosphorylation levels in T84 adhered to transfected Huvec cells. To determine whether another key signaling pathway was activated, whole cell extracts were prepared and immunoblotted with antibodies specifically recognizing the phosphorylated and active forms of ERK1/2. As shown in Figure $2 b$ (upper panel), adhesion of cancer cells to CHO-ES-WT cells activated the phosphorylation of ERK1/2 2fold increase) as detected by phosphospecific antibodies against ERK1/2, whereas total ERK proteins remained unchanged (bottom panel). ERK 1/2 phosphorylation was strongly increased following adhesion of T84 cells to CHO-ES-S128R cells (2.5-fold increase).

To further confirm our biochemical results, E-Selectin-induced tyrosine phosphorylation was evaluated by immunofluorescence in cancer cells adhered to transfectants $\mathrm{CHO}$ cells. Figure 3 and Table III show an increase in immunostaining of T84 cells (arrows) plated on CHO-ES-S128R cells (c) that accompanies cancer cell spreading after $3 \mathrm{hr}$ from seeding compared to intensity of fluorescence of tumor cells plated on CHO-ES-WT $(b)$ and mock-transfected cells $(a)$.

\section{Discussion}

Several reports in the last few years have indicated that besides the imbalance in regulatory pathways because of activation of oncogenes or loss of tumor suppressor genes, cancer progression and clinical outcomes may be greatly modulated by functional alteration in key proteins often determined by genetic polymorphisms. ${ }^{25-27}$ Accordingly, our study found that a single nucleotide polymorphism in E-selectin gene is significantly associated with the presence of metastases in colon carcinoma patients suggesting a link between genetic host background and tumor-endothelial cell interaction.

Adhesion of circulating cancer cells with vascular endothelium is critical during early stages of the metastatic process. ${ }^{1}$ Data strongly suggest that E-selectin expression on activated endothelium may facilitate cancer cell seeding. ${ }^{28-30}$ Our hypothesis was that a functional polymorphism (associated with a variation in the structure and ligand affinity of the molecule) affecting E-selectin could influence cancer cell biological behavior and colon cancer risk. The Ser128Arg polymorphism in the E-selectin gene has been associated with a higher risk of severe atherosclerosis, ${ }^{15}$ myocardial infarction, ${ }^{31}$ ischemic cerebrovascular disease, ${ }^{32}$ enhanced coagulation and systemic lupus erythematosus ${ }^{20,33,34}$; pathologies where increased leukocyte-endothelial cells interaction are observed. From a biological point of view, this specific polymorphism has been demonstrated to exert a significant effect on ligand recognition and binding, as cell transfectants expressing the a561c E-selectin allele better support interactions with leukocytes under shear flow conditions. ${ }^{35}$ 


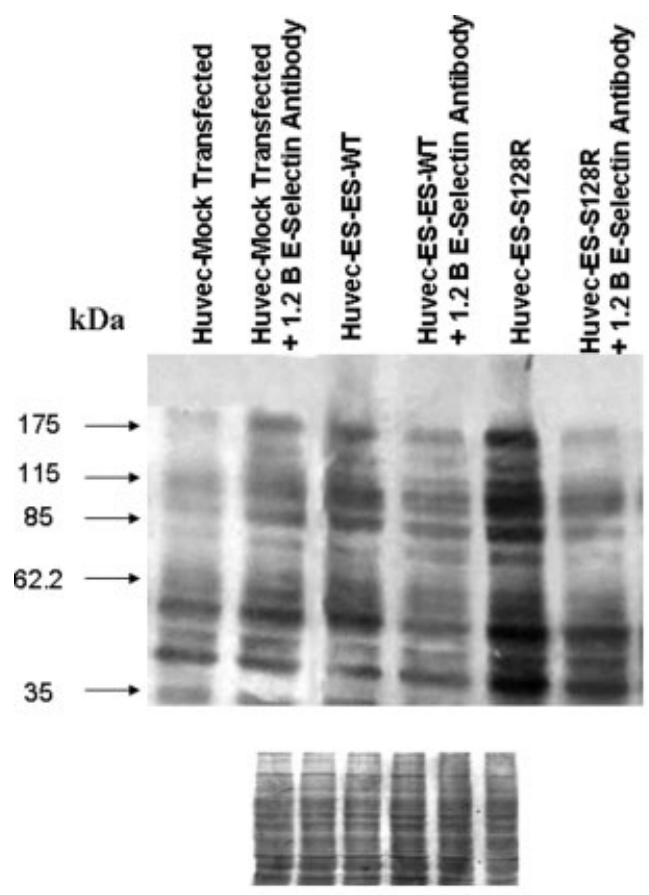

(a)

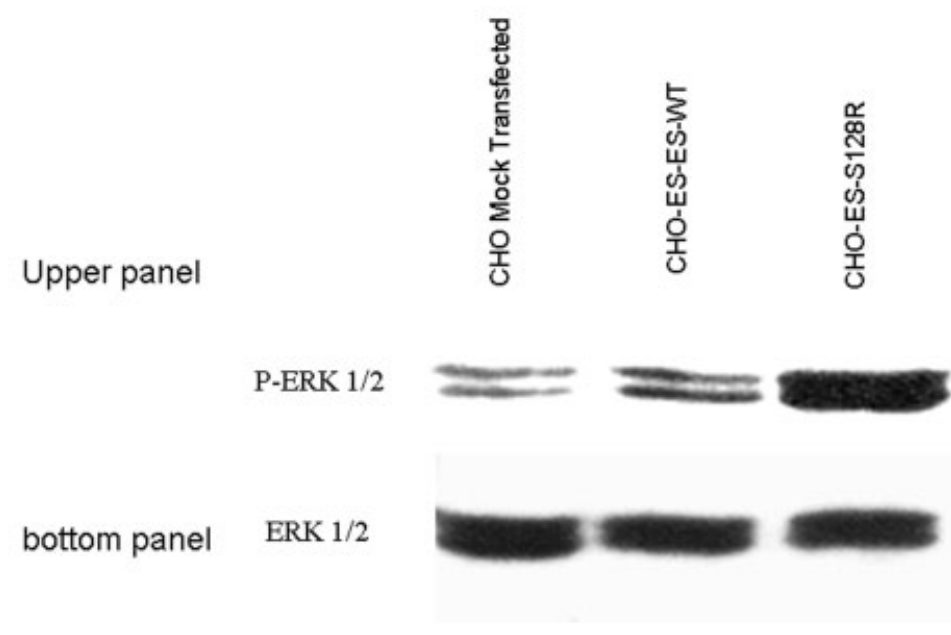

(b)

Figure 2 - Activation of cell signaling in T84 colon cancer cells after adhesion to transfectants Huvec cells. (a) Immunoprecipitation/western blot analysis for cell lysates from T84 cells plated on different transfectants Huvec cells showing a clear difference in the pattern of basal tyrosine phosphorylation (upper panel). Pounceau staining of the membrane is shown to ensure equal loading and transfer of proteins (bottom panel); (b) Addition of T84 cells to transfectants $\mathrm{CHO}$ is associated with increased phosphorylation of ERK 1/2. After adhesion to CHO cells, T84 cancer cells were harvested, and the whole cell extracts were separated on a 12\% SDS-PAGE gel. The blots were probed with antibodies against phospho-specific ERK1/2 (upper panel) or nonphosphorylated ERK1/2 as indicated. These blots are representative of 3 independent experiments. Total ERK in these experiments also serves as control for loading and transfer of proteins. Columns, mean densitometer quantification of the fold stimulation values relative to the control culture; bars, SD. ${ }^{*} p<0.05 ; * p<0.005$ (bottom panel).

Colorectal cancer (CRC) is one of the leading causes of mortality and accounts for $\sim 200,000$ deaths per year in Europe and USA. ${ }^{36}$ CRC is probably the type of cancer for which the most is known about the genes affected by somatic mutations, their normal functions and their carcinogenic effects when mutated; limited evidence is available about the influence of genetic polymorphisms on clinical outcome, most of the studies have been focused on genes encoding for metabolism enzymes as well as genes encoding DNA synthesis and repair enzymes. ${ }^{37}$ Selectins have been shown to play a critical role in tumor cell-endothelial cell interaction in CRC. ${ }^{38}$ No evidences have been produced on the role of the S128R polymorphism of E-selectin in cancer and more specifically in colon cancer. Our results suggest, for the first time to our knowledge, that individuals carrying the $128 \mathrm{R}$ allele of the E-selectin may present a higher risk, once they develop a tumor, to metastasis formation. The identification of new molecular markers of more aggressive colonic cancer phenotypes may in principle to individually tailor therapy to improve clinical outcome. These findings, whereas relevant, are preliminary. The small sample size requires to widen the screen and to include a higher number of patients. Furthermore, since metastasis formation depends by a number of adhesion molecules, any single mutation will only provide a small or modest contribution to the overall risk.

To correlate the increased colon metastasis risk with a functional role of this specific E-selectin polymorphism, we investigated if the expression in vitro of this variant form of E-selectin could amplify the adhesiveness of neoplastic cells to endothelial cells as well as alter downstream phosphorylation events. To examine this issue, we created an experimental model that used Huvec cells that were engineered to express wild-type E-selectin or S128R variant E-selectin. We found that S128R polymorphism of E-selectin significantly enhanced the adhesion of T84 colon cancer cells compared to WT E-selectin and mock vector.

The involvement of E-selectin in the adhesion of T84 colon cancer cells to Huvec monolayer was supported by the observation that pretreating Huvec cells with an anti-E-selectin neutralizing antibody, but not with a matched isotype antibody, inhibited the adhesion of tumor cells. The incomplete inhibition of adhesion by the neutralizing antibody can be explained with the presence of other adhesion molecules on endothelial cell surface affecting the attachment of T84 cells on Huvec.

Data in the literature have demonstrated that the ability of colon cancer cells to bind to E-selectin expressed on activated endothelial cells is directly proportional to their metastatic potential. ${ }^{39}$ Although a stronger adhesion of cancer cells to the endothelial cell surface should theoretically compromise their ability to move and migrate in the target organ, it is noteworthy to observe that evidence of the last years has demonstrated that surviving metastatic cells proliferate intravascularly after adhesion to the endothelium, and extravasation of the tumor occurs when intravascular micrometastatic foci outgrow the vessels they are in. ${ }^{40,41}$

In this framework our findings that S128R variant form of Eselectin determines an increased adhesion of neoplastic cells compared to the wild-type allele add a new level of investigations to the role of selectins in metastatic process.

Transendothelial migration by tumor cells requires a coordinated series of steps including: cancer attachment to the endothelial cell surface, modifications of the cytoskeletal organization, detachment from the substrate and active migration into the host connective tissue. The ability of cancer cells to respond to a variety of chemoattractant molecules in an autocrine and/or paracrine manner is well known; several growth factors as well 

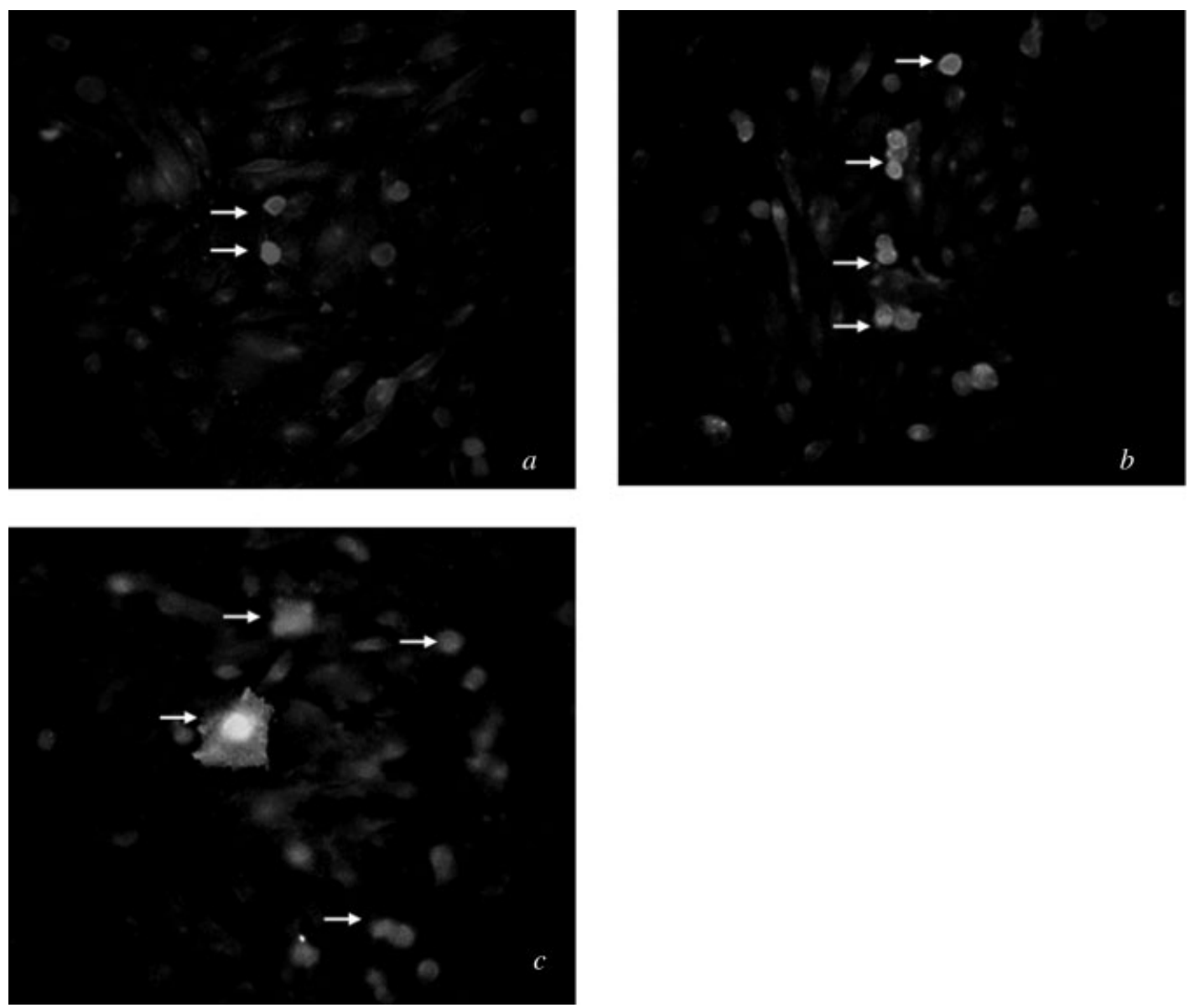

Figure 3 - Immunolocalization of tyrosine-phosphorylated proteins in T84 colon carcinoma cells after adhesion to transfectants CHO. Adhesion of T84 cells (arrows) to CHO-ES-S128R monolayer $(c)$ resulted in an increase of cytoplasmic and nuclear staining for phosphotyrosine compared to immunostaining observed for the cells adhering to CHO-ES-WT $(b)$ and mock-transfected CHO cells $(a)$. In Table III, it is indicated as percent $(\%)$ of increase, the quantification of fluorescence intensities in the different samples. Cells were stained with PY20 and FITCconjugated secondary antibody as described in Materials and methods section. Adhering T84 colon carcinoma cells are indicated with white arrows.

as extracellular matrix components have been shown to stimulate tumor cells chemotaxis and haptotaxis. ${ }^{42}$ The role of selectins as chemoattractants for nonimmune cells has not been well studied. P-selectin has been shown to induce endothelial cell motility $^{43}$ while E-Selectin was recently demonstrated to enhance motogenic potential of HT-29 cells by activation of stress-activated protein kinase and ERK pathways. ${ }^{6,44}$ To examine the hypothesis that the shed extracellular domain of polymorphic E-selectin might play a role in T84 cell motility, we performed a series of chemotaxis assays in the Boyden chamber system using the $\mathrm{CM}$ of transfectants $\mathrm{CHO}$ cells as the chemoattractant. We found that CM from S128R E-selectin-expressing $\mathrm{CHO}$ cells possesses a higher chemotactic activity compared to CM from WT E-selectin-expressing CHO cells and mock-transfected $\mathrm{CHO}$ cell controls. The incubation of the $\mathrm{CM}$ with an anti-E-selectin antibody significantly decreased cancer cell chemotaxis when compared to incubation with an isotype control antibody indicating that sE-selectin contributes to the CM chemotactic activity for tumor cells.

The evidence that E-Selectin can induce chemotaxis in cancer cells appears relevant for formation of metastases. Serum E-Selectin levels are known to be elevated in patients with various cancers, reflecting the enhanced expression of E-Selectin in the vessel
TABLE III - QUANTIFICATION OF FLUORESCENCE INTENSITIES IN T84 ADHERING TO TRANSFECTED CHO CELLS

\begin{tabular}{lc}
\hline \multicolumn{1}{c}{ Cell type } & Fluorescence increase in \% \\
\hline Mock-transfected CHO & 100 \\
CHO-ES-WT & $146( \pm 11)$ \\
CHO-ES-S128R & $163( \pm 17)$ \\
\hline
\end{tabular}

walls of these patients. ${ }^{45,46}$ The circulating soluble E-Selectin may thus not only be a sign of the augmented release of this molecule from the endothelium but also may provide a soluble stimulant of motility to direct cancer cells to the target organ.

Different studies have shown that intact, transmembrane Eselectin can transduce signals in endothelial cells during leukocyte recruitment. ${ }^{47,48}$ Little information has been gathered regarding the signal transduction pathways activated by interaction of E-selectin with the counter-receptor. Kumar et al. showed that soluble E-selectin mediates monocytes recruitment through the activation of Src-MAPK pathway. ${ }^{24}$ Koch and coworkers have reported that soluble E-selectin induces angiogenesis in vivo and stimulates in vitro the motility and tube formation of human dermal microvascular endothelial cells through Src- and phosphatidylinositol 3-kinase-mediated pathways. ${ }^{49}$ In cancer cells, the interaction of HT-29 colon carcinoma cells with $\mathrm{TNF} \alpha$-treated 
HUVEC cells activates the MAPK SAPK2/p38 pathway leading to transendothelial migration. ${ }^{4450}$ We previously demonstrated that the addition of E-selectin to colon cancer cells produces a 2fold increase in $\left[\mathrm{Ca}^{2+}\right]_{i}$ that affects cytoskeleton reorganization, cancer cell motility and tyrosine phosphorylation events in the cells. $^{21}$ Our present results, while confirming the activation of signaling pathways in cancer cells stimulated by binding of Eselectin, show that S128R polymorphism causes an increase in tyrosine phosphorylation-mediated pathways and ERK 1/2 signaling compared to WT E-selectin- and mock-transfected $\mathrm{CHO}$ cells.

Angiogenesis is critical in the development of tumors, recent data have demonstrated that $\mathrm{sE}$-selectin is a potent angiogenic mediator, acting predominantly through the Src-PI3K pathway ${ }^{24,49}$; it will be interesting to test whether polymorphic E-selectin is able to modulate the formation of blood vessels thus to affect the metastatic process also through revascularization.
In conclusion, our study, although needs to be validated in a larger cohort, suggests that the presence of the E-selectin $\mathrm{Arg}^{128}$ allele may be a facilitating factor for cancer metastasis in colon cancer patients.

\section{Acknowledgements}

We thank Prof. J. Medin for critical comments, Dr. M. Milazzo for help in the statistical analysis, Dr G. Kansas for E-selectin cDNA, Dr. Monica D'Amato for CHO-ES-WT cell preparation and Prof. D. Lio for healthy controls DNA. F.D and C.C are PhD students in Immunopharmacology at the Università of Palermo. This work was supported by Italian Association for Cancer Research (AIRC) to R.A. and G.D.L., Università di Palermo (International Cooperation) to R.A. and A.M.F.; ex $60 \%$ MURST to R.A., A.M.F. and to G.D.L.

\section{References}

1. Chambers AF, Groom AC, MacDonald IC. Metastasis: dissemination and growth of cancer cells in metastatic sites. Nat Rev Cancer 2002; 2:563-72.

2. Orr FW, Wang HH, Lafrenie RM, Scherbarth S, Nance DM. Interactions between cancer cells and the endothelium in metastasis. J Pathol 2000;190:310-29.

3. Krause T, Turner G. Are selectins involved in metastasis? Clin Exp Metastasis 1999; 17:183-92.

4. Burdick M, McCaffery J, Kim Y, Bochner B, Konstantopoulos K. Colon carcinoma cell glycolipids, integrins, and other glycoproteins mediate adhesion to HUVECs under flow. Am J Physiol Cell Physiol 2003;284:C977-87.

5. Kim Y, Borsig L, Han H, Varki N, Varki A. Distinct selectin ligands on colon carcinoma mucins can mediate pathological interactions among platelets, leukocytes, and endothelium. Am J Pathol 1999;155: 461-72.

6. Laferriere J, Houle F, Huot J. Regulation of the metastatic process by E-selectin and stress-activated protein kinase-2/p38. Ann NY Acad Sci 2002;973:562-72.

7. Voura E, Sandig M, Siu C. Cell-cell interactions during transendothelial migration of tumor cells. Microsc Res Tech 1998;43:265-75.

8. Bird M, Foster M, Priest R, Malhotra R. Selectins: physiological and pathophysiological roles. Biochem Soc Trans 1997;25:1199-206.

9. Alessandro R, Flugy A, Russo D, Stassi G, De Leo A, Corrado C, Alaimo G, De Leo G. Identification and phenotypic characterization of a subpopulation of T84 human colon cancer cells, after selection on activated endothelial cells. J Cell Physiol 2005;203:261-72.

10. Brodt P, Fallavollita L, Wolitzky B, Labow M. E-selectin is involved in liver colonization by metastatic carcinoma cells. Clin Exp Metastasis 1996; 14:74-5

11. Wittig B, Kaulen H, Thees R, Schmitt C, Knolle P, Stock J, Meyer Zum Bueschenfelde K, Dippold W. Elevated serum E-selectin in patients with liver metastases of colorectal cancer. Eur J Cancer 1996; 7:1215-18.

12. Yamada N, Chung Y, Takatsuka S, Arimoto Y, Sawada T, Dohi T, Sawa M. Increased sialyl Lewix A expression and fucosyltransferase activity with aquisitation of a high metastatic capacity in a colon cancer cell line. Br J Cancer 1997;76:582-4.

13. Iida A, Nakamura Y. High-resolution SNP map in the 55-kb region containing the selectin gene family on chromosome 1q24-q25. J Hum Genet 2003;48:150-4.

14. Vora D, Rosenbloom C, Beaudet A, Cottingham R. Polymorphisms and linkage analysis for ICAM-1 and the selectin gene cluster. Genomics 1994;21:473-7.

15. Wenzel K, Felix S, Kleber F, Brachold R, Menke T, Schattke S, Schulte K, Glaser C, Rohde K, Baumann G, Speer A. E-selectin polymorphism and atherosclerosis: an association study. Hum Mol Genet 1994;3:1935-7.

16. Ye S, Usher D, Virgil D, Zhang L, Yochim S, Gupta R. A PstI polymorphism detects the mutation of serine 128 to arginine in CD $62 \mathrm{E}$ gene-a risk factor for coronary artery disease. J Biomed Sci 1999; 6:18-21.

17. Revelle B, Scott D, Beck P. Single amino acid residues in the E- and P-selectin epidermal growth factor domains can determine carbohydrate binding specificity. J Biol Chem 1996;271:16160-70.

18. Winawer S, Fletcher R, Miller L, Godlee F, Stolar M, Mulrow C, Woolf S, Glick S, Ganiats T, Bond J, Rosen L, Zapka J, et al. Colorectal cancer screening: clinical guidelines and rationale. Gastroenterology 1997;112:594-642.
19. Kansas G, Pavalko F. The cytoplasmic domains of E- and P-selectin do not constitutively interact with alpha-actinin and are not essential for leukocyte adhesion. J Immunol 1996;157:321-5.

20. Hajeer A, El-Magadmi M, Alansari A, Bruce I E-selectin is a susceptibility gene for systemic lupus erythematosus (SLE). Arthritis Rheum 2000;43:S362.

21. D’Amato M, Flugy AM, Alaimo G, Bauder B, Kohn EC, De Leo G, Alessandro R. Role of calcium in E-selectin induced phenotype of T84 colon carcinoma cells. Biochem. Biophys Res Commun 2003; 301:907-14.

22. Flugy AM, D’Amato M, Russo D, Di Bella MA, Alaimo G, Kohn EC, De Leo G, Alessandro R. E-selectin modulates the malignant properties of T84 colon carcinoma cells. Biochem Biophys Res Commun 2002;293:1099-106

23. Blann A, Seigneur M. Soluble markers of endothelial cell function. Clin Hemorheol Microcirc 1997;17:3-11.

24. Kumar P, Hosaka S, Koch A. Soluble E-selectin induces monocyte chemotaxis through Src family tyrosine kinases. J Biol Chem 2001;276:21039-45.

25. Bond G, Hu W, Bond E, Robins H, Lutzker S, Arva N, Bargonetti J, Bartel F, Taubert H, Wuerl P, Onel K, Yip L, et al. A single nucleotide polymorphism in the MDM2 promoter attenuates the p53 tumor suppressor pathway and accelerates tumor formation in human. Cell 2004:119:591-602.

26. Bond $\mathrm{G}, \mathrm{Hu} \mathrm{W}$, Levine A. A single nucleotide polymorphism in the MDM2 gene: from a molecular and cellular explanation to clinical effect. Cancer Res 2005;65:5481-4.

27. Houlston R, Peto J. The search for low-penetrance cancer susceptibility alleles. Oncogene 2004;23:6471-6.

28. Belanger S, St-Pierre Y. Role of selectins in the triggering, growth, and dissemination of T-lymphoma cells: implication of L-selectin in the growth of thymic lymphoma. Blood 2005;105:4800-6.

29. Biancone L, Arak iM, Araki K, Vassalli P, Stamenkovic I. Redirection of tumor metastasis by expression of E-selectin in vivo. J Exp Med 1996;183:581-7.

30. Borsig L, Wong R, Hynes R, Varki N, Varki A. Synergistic effects of L- and P-selectin in facilitating tumor metastasis can involve nonmucin ligands and implicate leukocytes as enhancers of metastasis. Proc Natl Acad Sci USA 2002;99:2193-8.

31. Yoshida M, Takano Y, Sasaoka T, Izumi T, Kimura A. E-selectin polymorphism associated with myocardial infarction causes enhanced leukocyte-endothelial interactions under flow conditions. Arterioscler Thromb Vasc Biol 2003;23:783-8.

32. Hattori H, Sato H, Ito D, Tanahashi N, Murata M, Saito I, Watanabe K, Suzuki N. A561C polymorphism of E-selectin is associated with ischemic cerebrovascular disease in the Japanese population without diabetes mellitus and hypercholesterolemia. Brain Res 2006;1108:221-3.

33. Jilma B, Marsik C, Kovar F, Wagner O, Jilma-Stohlawetz P, Endler G. The single nucleotide polymorphism Ser128Arg in the E-selectin gene is associated with enhanced coagulation during human endotoxemia. Blood 2005;105:2380-3.

34. Marasini B, Casari S, Zeni S, Turri O, Biondi M. E-selectin polymorphism in autoiimune diseases. Arthritis Rheum 1999;42:S324.

35. Rao R, Clarke J, Ortlepp S, Robinson M, Landis R, Haskard D. The S128R polymorphism of E-selectin mediates neuraminidase-resistant tethering of myeloid cells under shear flow. Eur J Immunol 2002 32:251-60.

36. Nicum S, Midgley R, Kerr D. Colorectal cancer. Acta Oncol 2003; 42:263-75. 
37. Houlston R, Tomlinson I. Polymorphisms and colorectal tumor risk. Gastroenterology 2001;121:282-301.

38. Takada A, Ohmori K, Yoneda T, Tsuyuoka K, Hasegawa A, Kiso M, Kannagi R. Contribution of carbohydrate antigens sialyl Lewis A and sialyl Lewis X to adhesion of human cancer cells to vascular endothelium. Cancer Res 1993;53:354-61.

39. Sawada R, Tsuboi S, Fukuda M. Differential E-selectin-dependent adhesion efficiency in sublines of a human colon cancer exhibiting distinct metastatic potentials. J Biol Chem 1994;269:1425-3141.

40. Al-Mehdi AB, Tozawa K, Fisher AB, Shientag L, Lee A, Muschel RJ. Intravascular origin of metastasis from the proliferation of endotheliumattached tumor cells: a new model for metastasis. Nat Med 2000;6:100-2.

41. Wong C, Song C, Grimes M, Fu W, Dewhirst M, Muschel R, AlMehdi A. Intravascular location of breast cancer cells after spontaneous metastasis to the lung. Am J Pathol 2002;161:749-53.

42. Wells A. Tumor invasion: role of growth factor-induced cell motility. Adv Cancer Res 2000;78:31-101.

43. Morbidelli L, Brogelli L, Granger HJ, Ziche M. Endothelial cell migration is induced by soluble P-selectin. Life Sci 1998;62:7-11.

44. Laferriere J, Houle F, Huot J. Adhesion of HT-29 colon carcinoma cells to endothelial cells requires sequential events involving E-selectin and integrin beta4. Clin Exp Metastasis 2004;21:257-64.
45. Ye C, Kiriyama K, Mistuoka C, Kannagi R, Ito K, Watanabe T, Kondo K, Akiyama S, Takagi H. Expression of E-selectin on endothelial cells of small veins in human colorectal cancer. Int J Cancer 1995;61:455-60.

46. Sheen-Chen S, Eng H, Huang C, Chen W. Serum levels of soluble Eselectin in women with breast cancer. Br J Surg 2004;91:1578-81.

47. Hu Y, Szente B, Kiely J, Gimbrone MJ. Molecular events in transmembrane signaling via E-selectin. SHP2 association, adaptor protein complex formation and ERK1/2 activation. J Biol Chem 2001;276: 48549-53.

48. Cuvelier S, Paul S, Shariat N, Colarusso P, Patel K. Eosinophil adhesion under flow conditions activates mechanosensitive signaling pathways in human endothelial cells. J Exp Med 2005;202:86576.

49. Kumar P, Amin M, Harlow L, Polverini P, Koch A. Src and phosphatidylinositol 3-kinase mediate soluble E-selectin-induced angiogenesis. Blood 2003;101:3960-8.

50. Laferriere J, Houle F, Taher M, Valerie K, Huot J. Transendothelial migration of colon carcinoma cells requires expression of E-selectin by endothelial cells and activation of stress-activated protein kinase2 (SAPK2/p38) in the tumor cells. J Biol Chem 2001;276:3376272 